\title{
Isolation and Characterization of Methanohalophilus portucalensis sp. nov. and DNA Reassociation Study of the Genus Methanohalophilus
}

\author{
DAVID R. BOONE, ${ }^{1,2 *}$ INDRA M. MATHRANI, ${ }^{3} \dagger$ YITAI LIU,${ }^{1}$ JOSÉ A. G. F. MENAIA, ${ }^{1,4}$ \\ ROBERT A. MAH, ${ }^{3}$ AND JANE E. BOONE ${ }^{1}$
}

Departments of Environmental Science and Engineering ${ }^{1}$ and Chemical and Biological Sciences, ${ }^{2}$ Oregon Graduate Institute of Science \& Technology, 19600 N.W. von Neumann Drive, Beaverton, Oregon 970061999; School of Public Health, University of California, Los Angeles, California 90024 ${ }^{3}$; and Laboratório Nacional de Engenharia e Tecnologia Indústrial, Estrada das Palmeiras, 2745 Queluz, Portugal ${ }^{4}$

\begin{abstract}
Six strains of coccoid, halophilic methanogens were isolated from various salinaria and natural hypersaline environments. These isolates (strains FDF-1 ${ }^{\text {T }}$ [T = type strain], FDF-2, SF-2, Ret-1, SD-1, and Cas-1) grew on media containing methanol and mono-, di-, and trimethylamines as catabolic substrates, but not on media containing dimethyl sulfide, methane thiol, $\mathrm{H}_{2}$, formate, or acetate; when cells were provided with $\mathrm{H}_{2}$ in addition to methanol or trimethylamine, they grew on the medium containing a methyl substrate but did not catabolize $\mathrm{H}_{2}$. All of the strains were capable of growth in mineral medium to which trimethylamine was added as a catabolic substrate, although some strains were greatly stimulated by biotin or $p$-aminobenzoate. DNA

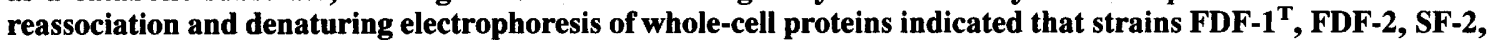
and Ret-1, together with previously described strains SF-1, Z-7302, Z-7401, Z-7404, and Z-7405, belong to a new taxon named Methanohalophilus portucalensis sp. nov; FDF-1 (= OCM 59) is the type strain. These strains grew fastest at temperatures near $40^{\circ} \mathrm{C}$ and, in medium containing 0.5 to $2.5 \mathrm{M} \mathrm{NaCl}$, at pH values near 7. The two new strains excluded from the species on the basis of the results of phylogenetic tests, strains Cas-1 and SD-1, also differed from $M$. portucalensis in some minor physiological characteristics. Strain Cas-1 was less halophilic (fastest growth occurred in the presence of 0.5 to $1 \mathrm{M} \mathrm{NaCl}$ ), and strain SD-1 was slightly alkaliphilic (fastest growth occurred at pH 7.8). The DNA reassociation study also showed that Methanohalophilus mahii SLP $^{\mathrm{T}}$ exhibited $52 \%$ sequence similarity with Methanohalophilus halophilus $\mathrm{Z}-7982^{\mathrm{T}}$, supporting the classification of these organisms as separate but closely related species.
\end{abstract}

Halophilic methylotrophic methanogens are classified in two genera of slight halophiles and one genus each of moderate and extreme halophiles. Members of the genera Methanolobus and Methanococcoides are slight halophiles of marine origin, growing fastest in the presence of less than $0.7 \mathrm{M} \mathrm{NaCl}(10,29,30)$. Members of the genus Methanohalophilus are moderately halophilic, growing fastest in the presence of 0.5 to $2.5 \mathrm{M} \mathrm{NaCl}$ (23), and members of the genus Methanohalobium are extremely halophilic, growing fastest in the presence of $\mathrm{NaCl}$ concentrations greater than 2 $M$ (36). No genus other than these four contains halophilic methylotrophic methanogens; although several halophiles were reported in the closely related genus Methanosarcina $(2,28)$, other studies indicated that these species are halotolerant rather than halophilic $(12,13)$. The genus Halomethanococcus has also been proposed (33), but we do not include it in our taxonomy because we have been unable to obtain the type strain of the only species described in this genus (Halomethanococcus doii) and because the name Halomethanococcus may be a subjective synonym of Methanohalophilus.

In addition to being unified by their halophily, which is recognized as an important taxonomic characteristic (4), the four recognized genera of halophilic methylotrophic methanogens share a coccoid morphology and several physiological characteristics. They are all methylotrophic, growing on

\footnotetext{
* Corresponding author.

† Present address: Instituttet for Bioteknologi, Danmarks Tekniske Højskole, DK-2800 Lyngby, Denmark.
}

media containing methanol and mono-, di-, and trimethylamines and sometimes on media containing dimethyl sulfide and methane thiol. Methanohalobium evestigatum is unable to grow in the presence of high concentrations of methanol (36), but in this study we showed that it can grow on medium containing $5 \mathrm{mM}$ methanol. These four halophilic methanogenic genera are the only taxonomic groups which contain members that are restricted to methylotrophic methanogenesis as their sole catabolic pathway (Methanosarcina strains can grow on medium containing acetate or $\mathrm{H}_{2}-\mathrm{CO}_{2}[14]$, and Methanosphaera strains grow only on medium containing methanol plus $\mathrm{H}_{2}$ [20]).

In this study we focused on the moderately halophilic genus, Methanohalophilus. The four species assigned previously to the genus Methanohalophilus are Methanohalophilus mahii Paterek and Smith 1988, 122 (the type species), Methanohalophilus halophilus (Zhilina 1984) Wilharm et al. 1991, 561, Methanohalophilus zhilinaeae Mathrani et al. 1988, 141, and Methanohalophilus oregonensis Liu et al. 1990,115 . The first two species are moderate halophiles that grow best at a neutral $\mathrm{pH}$, but the last two species are alkaliphiles that are only slightly halophilic. A sequence analysis of the $16 \mathrm{~S}$ rRNAs of these two alkaliphiles indicated that Methanohalophilus zhilinaeae belongs in a new genus and that Methanohalophilus oregonensis should be transferred to the genus Methanolobus (5). We describe here the isolation and characterization of several new moderately halophilic Methanohalophilus strains obtained from salinaria and a naturally hypersaline lake and river; we also phylogenetically compared these strains with the previously recognized species of the genus Methanohalophilus, as well as 
TABLE 1. Methanogenic strains used in this study and other moderately halophilic methanogens

\begin{tabular}{|c|c|c|c|c|c|}
\hline \multirow{2}{*}{ Strain } & \multicolumn{2}{|c|}{ Other designations } & \multirow{2}{*}{$\begin{array}{l}\text { DNA guanine-plus- } \\
\text { cytosine content } \\
\text { (mol\%) }\end{array}$} & \multirow{2}{*}{ Source } & \multirow{2}{*}{ Reference(s) } \\
\hline & $\mathrm{OCM}^{a}$ & $\mathrm{DSM}^{b}$ & & & \\
\hline Methanohalophilus mahii SLP ${ }^{\mathrm{T}}$ & $68^{\mathrm{T}}$ & $5219^{T}$ & & Great Salt Lake & 22 \\
\hline Methanohalophilus halophilus $\mathrm{Z}-7982^{\mathrm{T}}$ & $160^{\mathrm{T}}$ & $3094^{\mathrm{T}}$ & $41,44^{c}$ & Saline cyanobacterial mat & 34,35 \\
\hline Methanohalophilus portucalensis FDF- $1^{\mathrm{T}}$ & $59^{\mathrm{T}}$ & & & Salinarium & This study \\
\hline Methanohalophilus portucalensis FDF-2 & 66 & & 44 & Salinarium & This study \\
\hline Methanohalophilus portucalensis Ret-1 & 57 & & 43 & Retba Lake & This study \\
\hline Methanohalophilus portucalensis SF-1 & 13 & 3243 & 41 & Salinarium & 17 \\
\hline Methanohalophilus portucalensis SF-2 & 133 & & & Salinarium & This study \\
\hline Methanohalophilus portucalensis Z-7302 & 130 & 5701 & 42 & Chokrack Lake & 31,35 \\
\hline Methanohalophilus portucalensis Z-7401 & 131 & 5702 & 44 & & 31,35 \\
\hline Methanohalophilus portucalensis Z-7404 & 132 & 5699 & 43 & Chokrack Lake & 31,35 \\
\hline $\begin{array}{l}\text { Methanohalophilus portucalensis Z-7405 } \\
\text { Methanohalophilus sp. strain TR-7 }\end{array}$ & & 7302 & 44 & & 31,35 \\
\hline Methanohalobium evestigatum Z-7303 & $161^{\mathrm{T}}$ & $3721^{\mathrm{T}}$ & 37 & Saline cyanobacterial mat & $31,35,36$ \\
\hline Methanolobus sp. strain GS-16 & 58 & 6565 & & San Francisco Bay & 9,21 \\
\hline Cas-1 & 135 & & 42 & Casamance River & This study \\
\hline SD-1 & 134 & & 41 & Salinarium & This study \\
\hline Z-7301 & & 5700 & $45^{d}$ & Saline cyanobacterial mat & 31,35 \\
\hline Z-7305 & & & & Chokrack Lake & 31,35 \\
\hline Z-7402 & & & & Chokrack Lake & 31,35 \\
\hline Z-7403 & & & $40^{d}$ & Salt Lake, Kalmyk Steppe & 31,35 \\
\hline Z-7408 & & 5814 & $39^{d}$ & Sivash Lagoon & 31,35 \\
\hline
\end{tabular}

a OCM, Oregon Collection of Methanogens, Oregon Graduate Institute, Beaverton.

${ }^{b}$ DSM, Deutsche Sammlung von Mikroorganismen, Braunschweig, Germany.

${ }^{c}$ Data from references 31 and 35 .

${ }^{d}$ Data from reference 31 .

other unassigned strains, and propose a new species, Methanohalophilus portucalensis.

(Portions of the results have been presented previously, including the isolation and characterization of strain SD-1 $[16,18]$ and the isolation and characterization of strains FDF- $1^{\mathrm{T}}[\mathrm{T}=$ type strain], FDF-2, Ret-1, and Cas-1 $[16,19]$.)

\section{MATERIALS AND METHODS}

Sources of cultures and sediment samples. All of the following cultures used in this study are available from the Oregon Collection of Methanogens at the Oregon Graduate Institute (Table 1): strains Z-7302, Cas-1, FDF-1 ${ }^{\mathrm{T}}$, FDF-2, Ret-1, SD-1, SF-1, SF-2, and GS-16, Methanohalophilus mahii SLP ${ }^{\mathrm{T}}$, strains Z-7401, Z-7404, and Z-7405, and Methanohalophilus halophilus Z-7982 ${ }^{\mathrm{T}}$.

Inocula for isolation of new strains were collected from the upper $10 \mathrm{~cm}$ of sediments at several solar salterns, a saline lake, and a saline river. In some cases the subsurface sediments appeared to be uniformly anoxic (judged by their black color and sometimes also the appearance of gas bubbles), but when the dark color of the sediments was not uniform, we selected samples from the darkest areas. We filled sample collection bottles to the top with sediment and water, placed stoppers on the bottles, and returned the bottles to the laboratory for inoculation of enrichment cultures.

We collected samples from pond 20 at the solar salterns of the Leslie Salt Company in south San Francisco Bay (from which strain SF-2 was isolated). The water in the lake contained $220 \mathrm{~g}$ of dissolved solids per liter at the time of sampling, its $\mathrm{pH}$ was 7 , and the pond water was red (presumably because of the presence of photosynthetic halophilic microbes). Samples from pond 7A of a solar saltern at Western Salt Works in San Diego, Calif., yielded strain SD-1. The water in the pond contained $200 \mathrm{~g}$ of dissolved solids per liter, and its pH was 7.7. Decomposing bodies of brine shrimp (Artemia salina) were present on the surface of the sediment; brine shrimp tissue contains high concentrations of trimethylamine oxide, a precursor of trimethylamine in anoxic environments. Strains FDF- ${ }^{\mathrm{T}}$ and FDF-2 were isolated from sediments from two ponds of a salinarium at Figueira da Foz, Portugal. The water of the ponds was slightly pink (presumably because of the presence of phototrophic halophilic microbes), and the water was saturated with $\mathrm{NaCl}$ (crystals appearing to be $\mathrm{NaCl}$ were present in the sediments). The water contained $300 \mathrm{~g}$ of dissolved solids per liter, and the $\mathrm{pH}$ was 7 . Strain Ret-1 was isolated from sediments from Retba Lake, Senegal. Retba Lake is hydraulically fed by marine groundwater from the nearby Atlantic Ocean. The high evaporation rate in the lake results in year-round saturation with $\mathrm{NaCl}$. At the time of sampling, the lake water contained $450 \mathrm{~g}$ of dissolved solids per liter, and the $\mathrm{pH}$ was 7.3 . The lake water was pink, and gas bubbles collected from the sediments contained methane. Bernard Ollivier collected sediments from the Casamance River in Senegal in June 1986. Strain Cas-1 was isolated from sediments from the Casamance River, a major river draining southern Senegal. During the dry season, freshwater flow is low, and saltwater intrusion extends inland up to $200 \mathrm{~km}$. High rates of evaporation result in a net flow up-river in the lower part of the river, resulting in hypersaline conditions. This site differs from the others in that it has a lower concentration of dissolved solids (190 $\mathrm{g} /$ liter), and it is the only site which contained significant quantities of decaying macrophytes.

Culture methods. The Hungate roll tube methods were used with serum tubes and bottles closed with butyl rubber stoppers (7). Additions to media and inoculations were made with glass syringes flushed with $\mathrm{O}_{2}$-free gas. To isolate predominant methanogens from sediments, the samples were serially diluted into enrichment medium, and enrich- 
ment cultures were maintained from the highest dilutions which formed methane upon incubation. Organisms were isolated from such enrichment cultures by serial dilution, inoculation of roll tube medium, and incubation until colonies formed. Methanogenic colonies were tentatively identified by observing the roll tubes by epifluorescent microscopy with a Zeiss Universal microscope equipped with a type $\mathrm{O} 2$ filter set. Colonies were picked with a modified Pasteur pipet (7) and transferred to sterile medium in an open tube flushed with $\mathrm{O}_{2}$-free gas. The tube was aseptically closed with a stopper, serial dilutions were made in sterile medium, and roll tubes were inoculated from the dilutions. When methanogenic colonies were visible, we repeated the picking, dilution, and roll tube culturing procedures until a single colony type remained (except that subsurface colonies differed in appearance from surface colonies) and then repeated these procedures at least two additional times to ensure purity. The resulting pure cultures were deposited in the Oregon Collection of Methanogens.

For enrichment and isolation, cultures were incubated statically at $37^{\circ} \mathrm{C}$. Otherwise, cultures were grown statically at $42^{\circ} \mathrm{C}$, except that cultures containing added $\mathrm{H}_{2}$ were incubated on a shaker.

Culture media. Enrichment media were prepared by using site water and (per liter) $1 \mathrm{~g}$ of $\mathrm{NH}_{4} \mathrm{Cl}, 0.4 \mathrm{~g}$ of $\mathrm{K}_{2} \mathrm{HPO}_{4}, 3 \mathrm{~g}$ of $\mathrm{MgCl}_{2} \cdot 6 \mathrm{H}_{2} \mathrm{O}, 0.5 \mathrm{~g}$ of $\mathrm{CaCl}_{2} \cdot 2 \mathrm{H}_{2} \mathrm{O}, 10 \mathrm{ml}$ of a trace mineral solution (6), and $0.2 \mathrm{~g}$ of yeast extract. The media were dispensed into individual vessels along with a gas mixture containing $\mathrm{N}_{2}$ and $\mathrm{CO}_{2}(4: 1)$, the vessels were closed with stoppers, and the preparations were autoclaved. After the media cooled and $1 \mathrm{~h}$ to $18 \mathrm{~h}$ before inoculation, we added catabolic substrates from concentrated anoxic stock solutions, as well as $2.5 \mathrm{ml}$ of a sodium sulfide solution (100 $\mathrm{g}$ of $\mathrm{Na}_{2} \mathrm{~S} \cdot 9 \mathrm{H}_{2} \mathrm{O}$ per liter) per liter of medium. The final $\mathrm{pH}$ was 7.2. For strains FDF-1 ${ }^{\mathrm{T}}$ and FDF-2 the enrichment medium was modified by diluting the site water $1: 1$ with deionized water before the medium was prepared.

The media used for isolations in roll tubes were the same as enrichment medium except that they were prepared from a 1:1 dilution of site water and had $20 \mathrm{~g}$ of purified agar added per liter of medium. Most characterization studies were done with HS medium (17); the exceptions were the studies for vitamin requirements, which were done with $\mathrm{MH}$ medium (3) modified by eliminating Trypticase peptone, yeast extract, and coenzyme $M$. To determine optimal conditions for growth, we adjusted the $\mathrm{pH}$ by varying the $\mathrm{CO}_{2}$ content of the gas (to give $\mathrm{pH}$ values between 6.4 and 8.3) or by adding $1 \mathrm{M} \mathrm{NaOH}$ to medium with $\mathrm{N}_{2}$ gas or $1 \mathrm{M} \mathrm{HCl}$ to medium with $\mathrm{CO}_{2}$ gas to give more extreme $\mathrm{pH}$ values.

Determination of specific growth rates. Specific growth rates were calculated from exponential increases in accumulated methane levels, taking into account the methane formed by the inoculum culture prior to its transfer (24). Methane was quantified by gas chromatographic analysis of samples collected at the pressure of the vessels, thereby giving values for amount of methane per volume of headspace rather than per volume of gas under standard conditions. Samples were collected in pressure lock syringes and were detected by thermal conductivity (1) or by a sampling loop with flame ionization detection (12). Specific growth rates were calculated by least-squares analysis of the rate of increase of the logarithm of accumulated methane level. Whenever the specific growth rate of a culture was much lower than that of its inoculum, we transferred this culture during late logarithmic phase to medium under the same conditions and measured growth again. Also, the shapes of the growth curves from which specific growth rates were calculated always indicated logarithmic growth.

Guanine-plus-cytosine content of DNA. Cells were lysed by adding $0.1 \mathrm{~g}$ of sodium dodecyl sulfate per liter of cell pellet, and DNA was extracted with chloroform and isoamyl alcohol (15). Buoyant density was measured in $\mathrm{CsCl}$ gradients immobilized after centrifugation by polymerization of acrylamide (25). The guanine-plus-cytosine content was calculated from the buoyant density (27) by comparison with DNAs from Clostridium perfringens ( $\rho$ was assumed to be $1.691 \mathrm{~g} / \mathrm{cm}^{3}$; Sigma Chemical Co., St. Louis, Mo.) and "Micrococcus lysodeikticus" ( $\rho$ was assumed to be 1.731 $\mathrm{g} / \mathrm{cm}^{3}$; Sigma).

Antibiotic susceptibility. Anoxic, filter-sterilized solutions of antibiotics were added to cultures in mid-logarithmic phase, giving a final concentration of $100 \mathrm{mg} /$ liter. Methane formation was measured for 7 days. The apparent specific growth rates were compared with the growth rates of control cultures grown without antibiotics. Inhibited cultures were always transferred to fresh medium without antibiotics to determine whether any cells remained viable, and in these cases growth always occurred.

Organic nutrient requirements. In order to determine the minimum organic nutrients required for growth, we measured the specific growth rates of cultures grown for at least four transfers ( $2 \%$ inoculum by volume) in mineral medium to which $20 \mathrm{mM}$ trimethylamine was added as a catabolic substrate. For strains which grew substantially more slowly in the mineral medium than in the complex medium, we tested the effect of a vitamin mixture (6) or one or more of its constituent vitamins on the specific growth rates of these cultures.

Electrophoretic analysis of whole-cell proteins. Whole-cell proteins were extracted from cell pellets lysed by adding 0.5 $\mathrm{g}$ of sodium dodecyl sulfate per liter. Approximately $25 \mu \mathrm{g}$ of protein was added per well of a polyacrylamide gel, and proteins were separated as described previously (11). The gel was stained with Coomassie blue (11). The proteins bands were analyzed by measuring the position of each band and noting its density (light, medium, or dark). The level of similarity between a pair of organisms was calculated by the following algorithm: for each light protein band from the first organism, 1 point was added if the second organism had any band within $0.5 \mathrm{~mm}$ of the position of this light protein band; for each medium band from the first organism, 2 points was added for a medium or dark band within $0.5 \mathrm{~mm}$, or 1 point was added for any band within $1 \mathrm{~mm}$; for each dark band from the first organism, 3 points was added for a dark band within $0.5 \mathrm{~mm}, 2$ points was added for a medium or dark band within $1 \mathrm{~mm}$, or 1 point was added for any band within $1.5 \mathrm{~mm}$. The percentage of protein similarity was calculated by dividing the actual points by the total possible points. For each pair of organisms, each organism was compared with the other, and the percentage of similarity for the pair was the average of the reciprocal determinations. From these binary percentages of similarity, a tree (see Fig. 5) was formed in the same way that the DNA reassociation tree was formed.

DNA reassociation. DNA was purified from cell pellets by the Marmur method (15) and was labeled with ${ }^{32} \mathrm{P}$-cytosine by extension of random primers (13). DNA reassociation experiments were done by using the $S 1$ nuclease protocols (32) developed by Johnson (8) and modified by Maestrojuán et al. (13). For each interstrain comparison, each member of the pair was labeled and tested with the cold DNA of the other strain, and the interspecies sequence similarity values 
given below are the averages of reciprocal determinations. In the comparison between Methanohalophilus mahii SLP ${ }^{\mathrm{T}}$ and Methanohalophilus halophilus Z-7982 ${ }^{\mathrm{T}}$, each reciprocal determination was repeated. The tree shown in Fig. 5 was developed by grouping the most closely related organisms first, and subsequently the level of phylogenetic relationship between organisms or a group and another group of organisms was determined as the average of all of the individual similarity values for each pair between the two groups.

Microscopy. Epifluorescence was determined microscopically by using a type O2 filter set (Carl Zeiss, Inc., Thornwood, N.Y.); this provided an excitation spectrum with a peak at $365 \mathrm{~nm}$, a cutoff at $395 \mathrm{~nm}$, and a 420-nm long-pass barrier filter.

\section{RESULTS}

Isolation and characterization of strain SD-1. A sediment suspension from a saltern in San Diego, Calif., was inoculated into enrichment medium supplemented with $20 \mathrm{mM}$ trimethylamine and enrichment medium supplemented with $50 \mathrm{mM}$ sodium acetate $(0.1 \mathrm{ml}$ of suspension in $50 \mathrm{ml}$ of culture medium). Cultures in medium containing trimethylamine produced detectable methane within 3 days and completed methane production within 15 days (the quantity of methane formed was near the amount stoichiometrically expected). No significant quantities of methane were formed in cultures in medium containing acetate within 30 days. An enrichment culture was developed from the trimethylaminecontaining culture by $5 \%$ transfers when methanogenesis was complete; we isolated strain SD-1 from this enrichment culture and deposited it in the Oregon Collection of Methanogens as strain OCM 134.

Surface colonies were $0.5 \mathrm{~mm}$ in diameter within 7 days, tannish yellow, round, convex, smooth, and shiny and had entire edges and grainy interiors. Subsurface colonies were similar but had a lenticular shape. The colonies fluoresced brightly when they were examined by epifluorescence microscopy, and the fluorescence did not fade. Cells in the exponential growth phase were refractile, irregular cocci (diameter, $1 \mu \mathrm{m}$ ) which occurred singly, in pairs, and in small regular tetragonal clumps. The cells stained gram negative and fluoresced when they were examined by epifluorescence microscopy, but the fluorescence faded after about $30 \mathrm{~s}$. Cultures stored in serum bottles at room temperature retained viability for at least 6 months. Cells were sensitive to lysis by osmotic shock or by the presence of 50 mg of sodium dodecyl sulfate per liter.

Strain SD-1 grew in medium containing trimethylamine, dimethylamine, monomethylamine, or methanol as the catabolic substrate. No growth occurred in medium supplemented with $50 \mathrm{mM}$ acetate, $100 \mathrm{kPa}$ of $\mathrm{H}_{2}$ plus $20 \mathrm{kPa}$ of $\mathrm{CO}_{2}$, or $5 \mathrm{mM}$ dimethyl sulfide as the catabolic substrate. When $100 \mathrm{kPa}$ of $\mathrm{H}_{2}$ plus trimethylamine was added as the catabolic substrate, cultures formed the same quantity of methane and grew at the same rate as controls in medium containing only trimethylamine. With trimethylamine as the catabolic substrate, the cells grew fastest at $42^{\circ} \mathrm{C}$ (Fig. 1), at pH 7.8 (Fig. 2), and in the presence of 0.9 to $3.5 \mathrm{M} \mathrm{Na}^{+}$(Fig. 3 ). Cells grew rapidly (specific growth rate, $0.015 \mathrm{~h}^{-1}$ ) in mineral medium with no organic compound other than trimethylamine added; vitamins did not stimulate growth.

Chloramphenicol inhibited the growth and methanogenesis of cells. Tetracycline, ampicillin, carbenicillin, cycloserine, erythromycin, and penicillin had no effect at a concentration of $100 \mathrm{mg} /$ liter.

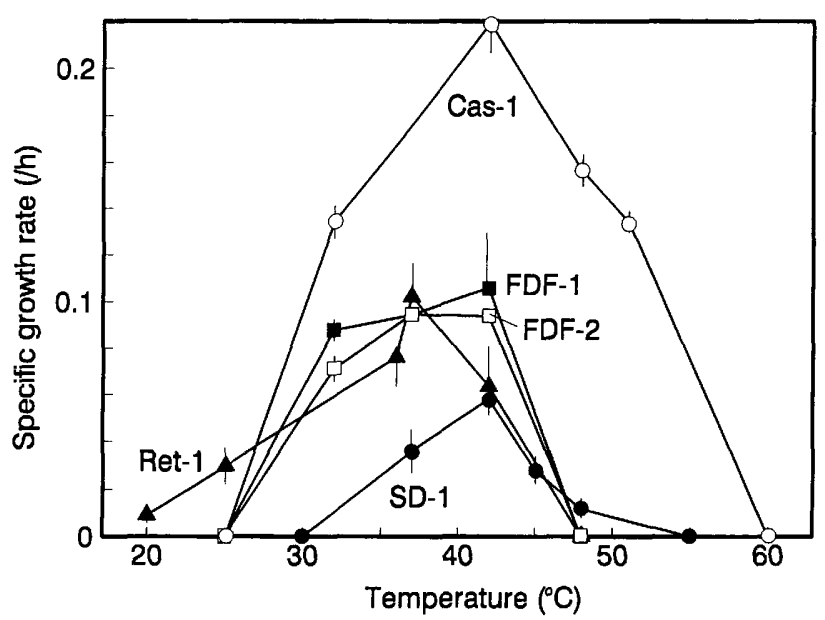

FIG. 1. Effect of temperature on specific growth rates of halophilic methanogens.

The guanine-plus-cytosine content of the DNA was 41 mol\%.

Isolation and characterization of strains FDF-1 ${ }^{\mathrm{T}}$ and FDF-2. The sediment suspension from the saltern at Figueira da Foz was serially diluted in enrichment medium containing $10 \mathrm{mM}$ trimethylamine and incubated at $37^{\circ} \mathrm{C}$. Cultures inoculated with $10 \mu \mathrm{l}$ or more of inoculum formed stoichiometric quantities of methane within 2 weeks. A culture which had received $10 \mu \mathrm{l}$ of inoculum was transferred to enrichment medium, and two methanogenic strains (strains FDF-1 ${ }^{\mathrm{T}}$ and FDF-2) were isolated. The following description applies to both strains. Colonies were $0.5 \mathrm{~mm}$ in diameter within 7 days of incubation at $37^{\circ} \mathrm{C}$. Surface colonies were circular, tannish yellow, convex, shiny, and opaque and had entire margins; subsurface colonies were lenticular. Cells were irregular cocci (diameter, 0.8 to $1.2 \mu \mathrm{m}$ ) and slightly refractile and stained gram negative. Cells occurred individually, in pairs, and in irregular clumps. Cells lysed in hypotonic medium and in the presence of $50 \mathrm{mg}$ of sodium dodecyl sulfate per liter.

Cells of strain FDF-1 ${ }^{\mathrm{T}}$ and FDF-2 grew in medium con-

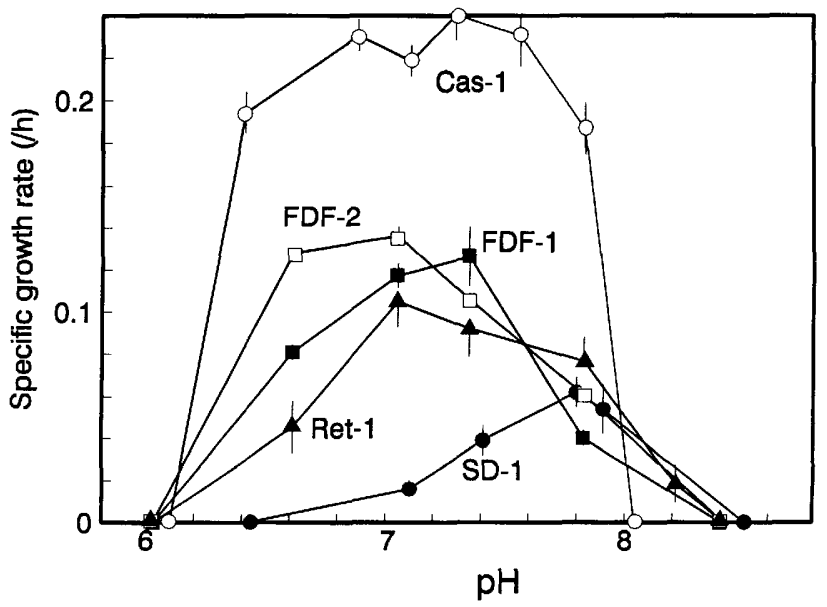

FIG. 2. Effect of $\mathrm{pH}$ on specific growth rates of halophilic methanogens. 


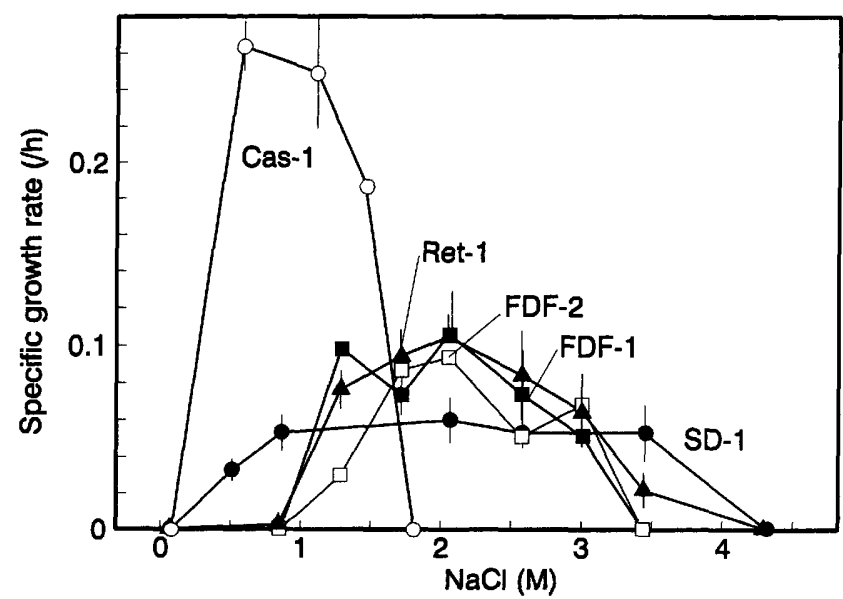

FIG. 3. Effect of salinity of specific growth rates of halophilic methanogens.

taining trimethylamine, dimethylamine, monomethylamine, or methanol as the substrate, but not in medium supplemented with acetate, $\mathrm{H}_{2}$, or dimethyl sulfide. The presence of $\mathrm{H}_{2}$ had no effect on methanogenesis from trimethylamine.

Both strains grew most rapidly in the presence of $2.2 \mathrm{M}$ $\mathrm{Na}^{+}$, and the range of $\mathrm{NaCl}$ concentrations giving good growth was narrower than the range of $\mathrm{NaCl}$ concentrations for some of the other halophilic methanogens (Fig. 3). Growth was also most rapid at 37 to $42^{\circ} \mathrm{C} \mathrm{(Fig.} \mathrm{1)} \mathrm{and} \mathrm{at} \mathrm{a} \mathrm{pH}$ of about 7.2 (Fig. 2).

Strains FDF-1 ${ }^{\mathrm{T}}$ and FDF-2 both grew well in mineral medium to which trimethylamine was added as the sole organic substrate (specific growth rates, $0.027 \mathrm{~h}^{-1}$ for FDF-1 ${ }^{\mathrm{T}}$ and $0.026 \mathrm{~h}^{-1}$ for FDF-2). Growth was almost as rapid in this medium as in $\mathrm{MH}$ medium, which contained yeast extract. The growth rate of these cultures in $\mathrm{MH}$ mineral medium supplemented with trimethylamine was not strongly stimulated by the presence of $5 \mathrm{mM}$ glycine betaine.

Chloramphenicol inhibited the growth of cells. Tetracycline, ampicillin, carbenicillin, cycloserine, erythromycin, and penicillin had no effect at a concentration of $100 \mathrm{mg} / \mathrm{liter}$.

The guanine-plus-cytosine content of the DNAs of strains FDF-1 and FDF-2 was 44 mol\%.

Isolation and characterization of strain Ret-1. The sediment suspension from Retba Lake was serially diluted in enrichment medium supplemented with $20 \mathrm{mM}$ trimethylamine and incubated at $37^{\circ} \mathrm{C}$. Cultures inoculated with $0.5 \mu l$ or more of inoculum formed stoichiometric quantities of methane within 3 weeks. Other cultures containing methanol as the catabolic substrate and inoculated in the same way also formed methane, but cultures in media containing acetate, $\mathrm{H}_{2}$, formate, propionate, butyrate, lactate, or cellulose did not form methane. The culture in medium containing trimethylamine as the substrate and inoculated with $0.05 \mu \mathrm{l}$ of inoculum was maintained as an enrichment culture in HS medium supplemented with $200 \mathrm{~g}$ of $\mathrm{NaCl}$ per liter $(3.5 \mathrm{M}$ $\mathrm{Na}^{+}$), and strain Ret-1 was isolated in $\mathrm{HS}$ agar medium supplemented with $150 \mathrm{~g}$ of $\mathrm{NaCl}$ per liter $\left(2.7 \mathrm{M} \mathrm{Na}^{+}\right)$. Colonies were $0.5 \mathrm{~mm}$ in diameter within 7 days when incubation was at $37^{\circ} \mathrm{C}$. Surface colonies were circular, tannish yellow, convex, shiny, and opaque and had entire margins; subsurface colonies were lenticular. Cells were irregular refractile cocci (diameter, $1 \mu \mathrm{m}$ ) which stained gram negative. Cells occurred mainly individually. Cells lysed in hypotonic medium and in the presence of $100 \mathrm{mg}$ of sodium dodecyl sulfate per liter.

Strain Ret-1 grew in medium containing trimethylamine, dimethylamine, monomethylamine, or methanol as the substrate, but not in medium containing acetate, $\mathrm{H}_{2}$, or dimethyl sulfide. The presence of $\mathrm{H}_{2}$ had no effect on methanogenesis from trimethylamine.

Cells grew most rapidly in the presence of $1.4 \mathrm{M} \mathrm{Na}^{+}$(Fig. 3), at $37^{\circ} \mathrm{C}$ (Fig. 1), and at pH 7.1 (Fig. 2).

Strain Ret-1 required biotin and $p$-aminobenzoate for good growth. It grew very poorly in $\mathrm{MH}$ mineral medium supplemented with trimethylamine (specific growth rate, 0.0057 $\mathrm{h}^{-1}$ ), but addition of the two vitamins together resulted in good growth (specific growth rate, $0.025 \mathrm{~h}^{-1}$ ). Growth was still not as rapid as as growth in MH medium (containing yeast extract and peptones; specific growth rate, $0.046 \mathrm{~h}^{-1}$ ).

Chloramphenicol and tetracycline inhibited the growth of cells. Ampicillin, carbenicillin, cycloserine, erythromycin, and penicillin had no effect at a concentration of $100 \mathrm{mg} / \mathrm{liter}$.

The guanine-plus-cytosine content of the DNA was 43 mol\%.

Isolation and characterization of strain Cas-1. The sediment suspension from the Casamance River was inoculated into $\mathrm{HS}$ medium containing $80 \mathrm{~g}$ of $\mathrm{NaCl}$ per liter $(1.5 \mathrm{M}$ $\mathrm{Na}^{+}$) and $20 \mathrm{mM}$ trimethylamine, and the preparation was incubated at $37^{\circ} \mathrm{C}$. Sediments inoculated into medium containing $120 \mathrm{~g}$ of $\mathrm{NaCl}$ per liter and $20 \mathrm{mM}$ trimethylamine did not form methane. Methanogenesis from the enrichment culture containing $80 \mathrm{~g}$ of $\mathrm{NaCl}$ per liter was complete within 7 days, and an enrichment culture was maintained by transfer in the same medium. Strain Cas-1 was isolated from this enrichment culture in HS agar medium containing $1.5 \mathrm{M}$ $\mathrm{NaCl}$.

Colonies were $1 \mathrm{~mm}$ in diameter within 7 days when incubation was at $37^{\circ} \mathrm{C}$. Surface colonies were circular, tannish yellow, convex, shiny, and opaque and had entire margins; subsurface colonies were lenticular. Cells were cocci (diameter, $1 \mu \mathrm{m}$ ) which stained gram negative and occurred mainly individually. Cells lysed in hypotonic medium and in the presence of $100 \mathrm{mg}$ of sodium dodecyl sulfate per liter.

Strain Cas-1 grew in medium containing trimethylamine, dimethylamine, monomethylamine, or methanol as the substrate. Cells grew poorly in mineral medium containing trimethylamine as the sole organic addition (specific growth rate, $0.015 \mathrm{~h}^{-1}$ ), but when biotin was added, they grew much faster $\left(0.060 \mathrm{~h}^{-1}\right)$.

Cells grew most rapidly in the presence of 0.6 to $1.5 \mathrm{M}$ $\mathrm{Na}^{+}$(Fig. 3), at $42^{\circ} \mathrm{C}$ (Fig. 1), and at pH 6.4 to 7.8 (Fig. 2).

Chloramphenicol inhibited the growth of cells. Tetracycline, ampicillin, carbenicillin, cycloserine, erythromycin, and penicillin had no effect at a concentration of $100 \mathrm{mg} / \mathrm{liter}$.

The guanine-plus-cytosine content of the DNA was 42 mol\%.

Isolation and characterization of strain SF-2. The sediment suspension from the saltern in San Francisco Bay was serially diluted and inoculated into enrichment medium supplemented with $20 \mathrm{mM}$ trimethylamine. Within 10 days bottles inoculated with the equivalent of $10 \mathrm{nl}$ of sediment slurry produced significant quantities of methane. This culture was maintained as an enrichment culture for several transfers before a coccoid methanogen (strain SF-2) was isolated from it.

Surface colonies were $0.5 \mathrm{~mm}$ in diameter within 7 days, tannish yellow, round, convex, smooth, and shiny and had entire edges and grainy interiors. Subsurface colonies were 

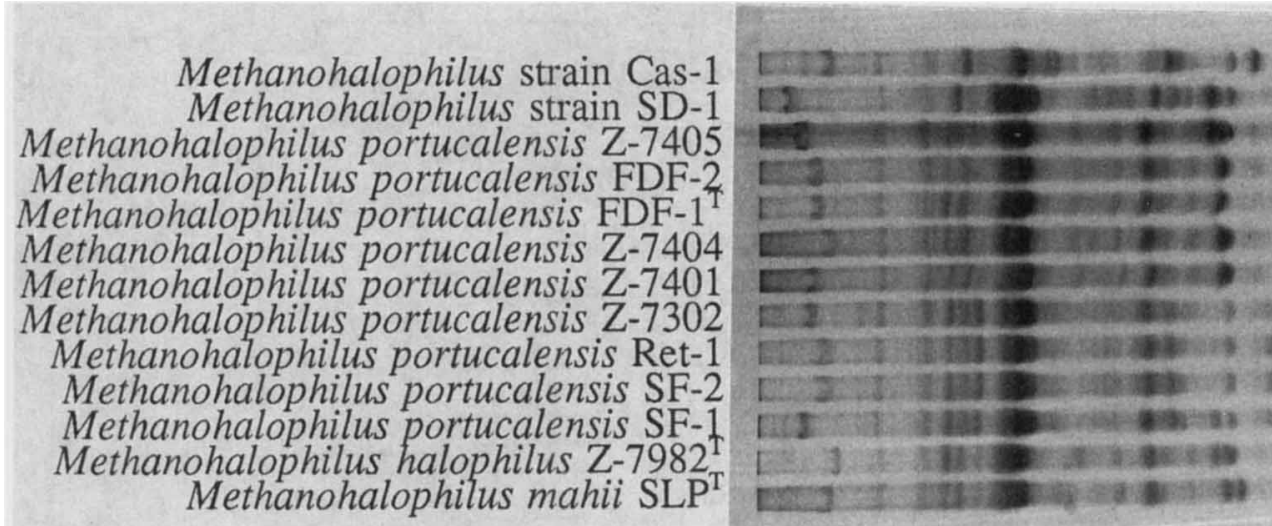

FIG. 4. Electrophoretic analysis of whole-cell proteins in the presence of sodium dodecyl sulfate.

similar but were lenticular. The colonies fluoresced brightly when they were examined by epifluorescence microscopy, and the fluorescence did not fade. Cells in the exponential growth phase were refractile, irregular cocci (diameter, 1 $\mu \mathrm{m})$ which occurred singly, in pairs, and in small regular tetragonal clumps. Cells stained gram negative and fluoresced when they were examined by epifluorescence microscopy, but the fluorescence faded after about $30 \mathrm{~s}$. Cultures stored in serum bottles at room temperature retained viability for at least 6 months. Cells were sensitive to lysis by osmotic shock or by the presence of $50 \mathrm{mg}$ of sodium dodecyl sulfate per liter.

Strain SF-2 grew in medium containing trimethylamine, dimethylamine, monomethylamine, or methanol as the catabolic substrate. No growth occurred in medium containing $50 \mathrm{mM}$ acetate, $100 \mathrm{kPa}$ of $\mathrm{H}_{2}$ plus $20 \mathrm{kPa}$ of $\mathrm{CO}_{2}$, or $5 \mathrm{mM}$ dimethyl sulfide as the catabolic substrate. When $100 \mathrm{kPa}$ of $\mathrm{H}_{2}$ plus trimethylamine was added as the catabolic substrate, cultures formed the same quantity of methane and grew at the same rate as controls in medium containing only trimethylamine. Cells in mineral medium containing trimethylamine as the only organic compound grew at a specific growth rate of $0.025 \mathrm{~h}^{-1}$, and growth was not stimulated by vitamins.

Vitamin requirements of other moderately halophilic methanogens. Strains Z-7401, Z-7404, Z-7302, Z-7982 ${ }^{\mathrm{T}}$, and SLP ${ }^{\mathrm{T}}$ were all able to grow in $\mathrm{MH}$ mineral medium containing trimethylamine as the substrate. Strains Z-7401 and Z-7404 grew rapidly in this medium (nearly as rapidly as in $\mathrm{MH}$ medium, which contains yeast extract and peptones), but the other strains grew very poorly. Strains $\mathrm{Z}-7982^{\mathrm{T}}$ and SLP ${ }^{\mathrm{T}}$ grew well in MH mineral medium containing trimethylamine when biotin was added. Strains Z-7302 and Ret-1 grew well only when mineral $\mathrm{MH}$ medium containing trimethylamine was supplemented with both biotin and $p$-aminobenzoate.

Growth of Methanohalobium evestigatum on medium containing methanol. Methanohalobium evestigatum Z-7303 ${ }^{\mathrm{T}}$ was not able to grow on medium containing $20 \mathrm{mM}$ methanol or in medium containing $20 \mathrm{mM}$ methanol plus $40 \mathrm{mM}$ trimethylamine. However, cells grew on medium containing $5 \mathrm{mM}$ methanol.

Analysis of whole-cell proteins. We used electrophoresis in denaturing gels to analyze the whole-cell proteins of a number of halophilic methanogens (Fig. 4). Our results revealed a high degree of diversity among these organisms in their proteins, although we distinguished two groups whose members exhibited similarities with each other. One group comprises strains FDF-1 ${ }^{\mathrm{T}}$, FDF-2, Z-7401, and Z-7404, and the other consists of strains Z-7302, Ret-1, and SF-2.

We prepared other protein gels to compare strain Cas-1 with the type strains of Methanolobus and Methanococcoides species (data not shown) because strain Cas-1 is more similar to members of these genera in its optimal salt concentration than it is to Methanohalophilus strains. However, the proteins of strain Cas-1 were more similar to those of the Methanohalophilus strains included in this study than to the proteins of Methanolobus or Methanococcoides strains.

DNA reassociation studies. The results of the DNA reassociation experiments are shown in Fig. 5. The DNA reassociation tree is consistent with the tree derived from a protein analysis (Fig. 5).

\section{DISCUSSION}

The methanogens investigated in this study, which include most of the known available moderately halophilic methanogens from $\mathrm{pH}$-neutral environments, were isolated from a wide variety of sources (Table 1). Yet all of these methanogens appear to be similar physiologically, having an identical substrate range and exhibiting similar growth responses to different $\mathrm{pH}$, salinity, and temperature conditions. These characteristics suggest that all of these strains, with the possible exceptions of strains Cas-1 and SD-1, should be classified as members of the genus Methanohalophilus. Strains Cas-1 and SD-1 differed from Methanohalophilus strains physiologically in some respects (strain Cas-1 grew more rapidly and was less halophilic, and strain SD-1 was slightly halophilic), and DNA reassociation studies revealed a phylogenetic separation (Fig. 5). We believe that the taxonomic assignment of these two strains should await rRNA sequence analysis.

Figure 5 also shows that Methanolobus sp. strain GS-16 and Methanohalobium evestigatum Z-7303 ${ }^{\mathrm{T}}$ were not closely related to the genus Methanohalophilus. Assignment of strain GS-16 to the genus Methanolobus rather than the genus Methanohalophilus is suggested by the results of a $16 \mathrm{~S}$ rRNA sequence analysis (26).

Taxonomy of Methanohalophilus mahii and Methanohalophilus halophilus. Methanohalophilus mahii and Methanohalophilus halophilus are physiologically very similar (22, $23,34,35$ ), and these names could be considered subjective 


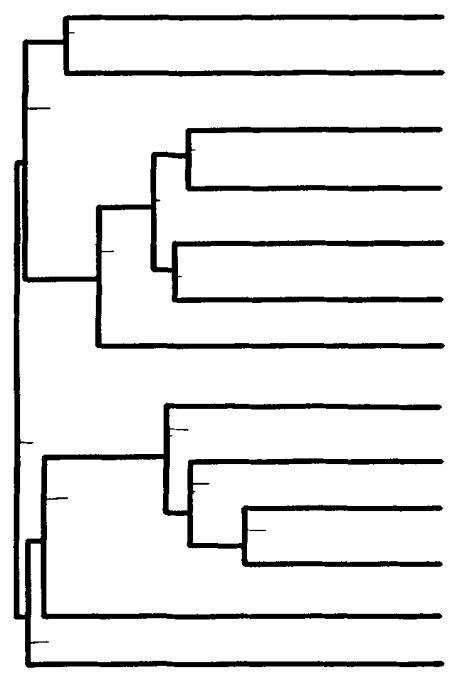

Methanohalophilus mahii SLP

Methanohalophilus halophilus Z-7982

Methanohalophilus portucalensis FDF-1

Methanohalophilus portucalensis FDF-2

Methanohalophilus portucalensis Z-7401

Methanohalophilus portucalensis Z-7404

Methanohalophilus portucalensis Z-7405

Methanohalophilus portucalensis Z-7302

Methanohalophilus portucalensis SF-1

Methanohalophilus portucalensis Ret-1

Methanohalophilus portucalensis SF-2

Strain Cas-1

Strain SD-1

Methanolobus strain GS-16

Methanohalobium evestigatum Z-7303

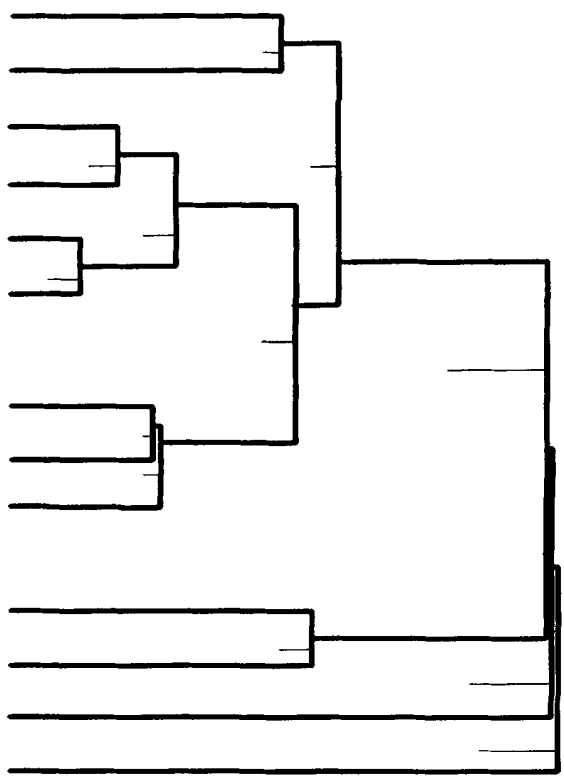

100
50

percent sequence similarity of DNA

Percent matching protein bands

FIG. 5. Trees based on similarity of proteins as analyzed by denaturing electrophoresis and on reassociation of DNAs of halophilic methanogens.

synonyms; however, we prefer to consider these organisms separate species. We found only $52 \%$ sequence similarity between their DNAs, a value much lower than the $87 \%$ similarity found in a single determination by Wilharm et al. (31). Additional evidence to support the current separation of these species came from the electrophoretic analysis of whole-cell proteins (Fig. 4 and 5), which indicated that there are considerable differences in proteins when the two strains are grown under identical conditions. Although these species are difficult to distinguish physiologically on the basis of known characteristics, our DNA reassociation results and protein analysis results suggest that unknown physiological differences probably exist. Thus, if we consider these names synonyms on the basis of our present physiological knowledge, we might in the near future separate them again on the basis of new information. Another problem in proposing the union of Methanohalophilus mahii and Methanohalophilus halophilus is that Methanohalophilus mahii is the type species of the genus Methanohalophilus, so this genus would be lost unless it was conserved by an opinion of the Judicial Commission. Therefore, in the interest of taxonomic stability, we continue to consider these taxa two separate species.

Taxonomy of other moderately halophilic methanogens. DNA reassociation and whole-cell protein analyses (Fig. 5) showed that strains Cas-1 and SD-1, Methanolobus sp. strain GS-16, and Methanohalobium evestigatum Z-7303 ${ }^{\mathrm{T}}$ were phylogenetically distant from the other strains included in this study. We propose that strains FDF-1 ${ }^{\mathrm{T}}$, FDF-2, Z-7302, Z-7401, Z-7404, Z-7405, SF-1, SF-2, and Ret-1 should be placed in a single species. Even though these strains can be divided into two groups that exhibit less than $60 \%$ between-group DNA sequence similarity, all of the strains are very similar physiologically and morphologically.

Description of Methanohalophilus portucalensis sp. nov.
Methanohalophilus portucalensis (por.tu.cal.ens'is. L. adj. portucalensis, from Portugal) cells are irregular, nonmotile, coccoid cells (diameter, 0.6 to $2 \mu \mathrm{m}$ ) and are gram negative. The coccoid cells occur singly, in pairs, or, less commonly, in small aggregates. Strictly anaerobic. Cells are sensitive to lysis by $0.2 \mathrm{~g}$ of sodium dodecyl sulfate per liter. The catabolic substrates include methanol and methylamines, but not $\mathrm{H}_{2}$ plus $\mathrm{CO}_{2}$, formate, acetate, methane thiol, or dimethyl sulfide. Cells grow in medium containing minerals plus trimethylamine as the sole organic substrate, but some strains require $p$-aminobenzoate, biotin, or both.

Growth is most rapid in medium containing 0.5 to $2 \mathrm{M}$ $\mathrm{NaCl}$, at $\mathrm{pH} 6.5$ to 7.5 , and at temperatures of about $40^{\circ} \mathrm{C}$.

The guanine-plus-cytosine content of the DNA is 43 to 44 mol\%.

The type strain is strain FDF-1 (= OCM 59), which was isolated from sediments from a salinarium in Figiera da Foz, Portugal.

\section{ACKNOWLEDGMENTS}

We thank Bernard Ollivier (INRA, ORSTOM, Marseilles, France) for collecting samples and for helpful discussions, Shuisong $\mathrm{Ni}$ (Oregon Graduate Institute) for technical help and discussions, and Thomas O. MacAdoo (Virginia Polytechnic Institute and State University) for checking the etymology of the epithet.

This study was funded in part by the Program in Energy from Biomass, funded by the Gas Research Institute and the University of Florida (grant IFAS-GRI-FIA-MCS 2171), and by the U.S. Geological Survey, Department of the Interior (grants 14-08-0001G1636 and 14-08-0001-G2098).

\section{REFERENCES}

1. Baresi, L., R. A. Mah, D. M. Ward, and I. R. Kaplan. 1978. Methanogenesis from acetate: enrichment studies. Appl. Environ. Microbiol. 36:186-197. 
2. Blotevogel, K.-H., U. Fischer, and K. H. Lüpkes. 1986. Methanococcus frisius sp. nov., a new methylotrophic marine methanogen. Can. J. Microbiol. 32:127-131.

3. Boone, D. R., R. L. Johnson, and Y. Liu. 1989. Diffusion of the interspecies electron carriers $\mathrm{H}_{2}$ and formate in methanogenic ecosystems and its implication in the measurement of $K_{m}$ for $\mathrm{H}_{2}$ or formate uptake. Appl. Environ. Microbiol. 55:1735-1741.

4. Boone, D. R., and W. B. Whitman. 1988. Minimal standards for describing new taxa within the genera of methanogenic bacteria. Int. J. Syst. Bacteriol. 38:212-219.

5. Boone, D. R., W. B. Whitman, and P. Rouvière. Diversity and taxonomy of methanogens. In J. G. Ferry (ed.), Methanogenesis, in press. Chapman \& Hall, New York.

6. Ferguson, T. J., and R. A. Mah. 1983. Isolation and characterization of an $\mathrm{H}_{2}$-oxidizing thermophilic methanogen. Appl. Environ. Microbiol. 45:265-274.

7. Hungate, R. E. 1969. A roll tube method for cultivation of strict anaerobes. Methods Microbiol. 3B:117-132.

8. Johnson, J. L. 1985. DNA reassociation and RNA hybridisation of bacterial nucleic acids. Methods Microbiol. 18:33-74.

9. Kiene, R. P., R. S. Oremland, A. Catena, L. G. Miller, and D. G. Capone. 1986. Metabolism of reduced methylated sulfur compounds in anaerobic sediments by a pure culture of an estuarine methanogen. Appl. Environ. Microbiol. 52:1037-1045.

10. König, H., and K. O. Stetter. 1982. Isolation and characterization of Methanolobus tindarius, sp. nov., a coccoid methanogen growing only on methanol and methylamines. Zentralbl. Bakteriol. Parasitenkd. Infektionskr. Hyg. Abt. 1 Orig. Reihe C 3:478-490.

11. Liu, Y., D. R. Boone, and C. Choy. 1990. Methanohalophilus oregonense sp. nov., a methylotrophic methanogen from an alkaline, saline aquifer. Int. J. Syst. Bacteriol. 40:111-116.

12. Maestrojuán, G. M., and D. R. Boone. 1991. Characterization of Methanosarcina barkeri MS $^{\mathbf{T}}$ and 227 , Methanosarcina mazei S-6 ${ }^{\mathrm{T}}$, and Methanosarcina vacuolata Z-761 ${ }^{\mathrm{T}}$. Int. J. Syst. Bacteriol. 41:267-274.

13. Maestrojuán, G. M., J. E. Boone, R. A. Mah, J. A. G. F. Menaia, M. S. Sachs, and D. R. Boone. 1992. Taxonomy and halotolerance of mesophilic Methanosarcina strains, assignment of strains to species, and synonymy of Methanosarcina mazei and Methanosarcina frisia. Int. J. Syst. Bacteriol. 42: 561-567.

14. Mah, R. A., and D. R. Boone. 1988. Methanosarcina, p. 2199-2205. In J. T. Staley, N. Pfennig, R. G. E. Murray, and J. G. Holt (ed.), Bergey's manual of systematic bacteriology, vol. 3. The Williams \& Wilkins Co., Baltimore.

15. Marmur, J. 1961. A procedure for the isolation of deoxyribonucleic acid from microorganisms. J. Mol. Biol. 3:208-218.

16. Mathrani, 1. M. 1989. Ph.D. thesis. University of California, Los Angeles.

17. Mathrani, I. M., and D. R. Boone. 1985. Isolation and characterization of a moderately halophilic methanogen from a solar saltern. Appl. Environ. Microbiol. 50:140-143.

18. Mathrani, I. M., D. R. Boone, and R. A. Mah. 1985. Isolation and characterization of a halophilic methanogen from a solar saltern, p. 160. Abstr. 85th Annu. Meet. Am. Soc. Microbiol. 1985.

19. Mathrani, I. M., D. R. Boone, and R. A. Mah. 1988. Isolation and characterization of four halophilic methanogens and DNA/ DNA homology studies of 12 halophilic methanogens. I-23, p.
184. Abstr. 88th Annu. Meet. Am. Soc. Microbiol. 1988.

20. Miller, T. L., and M. J. Wolin. 1985. Methanosphaera stadtmaniae gen. nov., sp. nov.: a species that forms methane by reducing methanol with hydrogen. Arch. Microbiol. 141:116122 .

21. Oremland, R. S., R. P. Kiene, I. M. Mathrani, M. J. Whiticar, and D. R. Boone. 1989. Description of an estuarine methylotrophic methanogen which grows on dimethyl sulfide. Appl. Environ. Microbiol. 55:994-1002.

22. Paterek, J. R., and P. H. Smith. 1985. Isolation and characterization of a halophilic methanogen from Great Salt Lake. Appl. Environ. Microbiol. 50:877-881.

23. Paterek, J. R., and P. H. Smith. 1988. Methanohalophilus mahii gen. nov., sp. nov., a methylotrophic halophilic methanogen. Int. J. Syst. Bacteriol. 38:122-123.

24. Powell, G. E. 1983. Interpreting gas kinetics of batch culture. Biotechnol. Lett. 5:437-440.

25. Preston, J. F., and D. R. Boone. 1973. Analytical determination of the buoyant density of DNA in acrylamide gels after preparative $\mathrm{CsCl}$ gradient centrifugation. FEBS Lett. 37:321-324.

26. Rouvière, P., L. Mandelco, S. Winker, and C. R. Woese. 1992. A detailed phylogeny for the Methanomicrobiales. Syst. Appl. Microbiol. 15:363-371

27. Schildkraut, C. L., J. Marmur, and P. Doty. 1962. Determination of the base composition of deoxyribonucleic acid from its buoyant density in CsCl. J. Mol. Biol. 4:430-433.

28. Sowers, K. R., S. F. Baron, and J. G. Ferry. 1984. Methanosarcina acetivorans sp. nov., an acetotrophic methane-producing bacterium isolated from marine sediments. Appl. Environ. Microbiol. 47:971-978.

29. Sowers, K. R., and J. G. Ferry. 1983. Isolation and characterization of a methylotrophic marine methanogen, Methanococcoides methylutens gen. nov., sp. nov. Appl. Environ. Microbiol. 45:684-690.

30. Sowers, K. R., J. L. Johnson, and J. G. Ferry. 1984. Phylogenetic relationships among the methylotrophic methane-producing bacteria and emendation of the family Methanosarcinaceae. Int. J. Syst. Bacteriol. 34:444-450.

31. Wilharm, T., T. N. Zhilina, and P. Hummel. 1991. DNA-DNA hybridization of methylotrophic halophilic methanogenic bacteria and transfer of Methanococcus halophilus VP to the genus Methanohalophilus as Methanohalophilus halophilus comb. nov. Int. J. Syst. Bacteriol. 41:558-562.

32. Xun, L., D. R. Boone, and R. A. Mah. 1989. Deoxyribonucleic acid hybridization study of Methanogenium and Methanocorpusculum species, emendation of the genus Methanocorpusculum, and transfer of Methanogenium aggregans to the genus Methanocorpusculum as Methanocorpusculum aggregans comb. nov. Int. J. Syst. Bacteriol. 39:109-111.

33. Yu, I. K., and F. Kawamura. 1987. Halomethanococcus doii gen. nov., sp. nov: an obligately halophilic methanogenic bacterium from solar salt ponds. J. Gen. Appl. Microbiol. 33:303309 .

34. Zhilina, T. N. 1983. A new obligate halophilic methane-producing bacterium. Mikrobiologiya 52:375-382.

35. Zhilina, T. N. 1986. Methanogenic bacteria from hypersaline environments. Syst. Appl. Microbiol. 7:216-222.

36. Zhilina, T. N., and G. A. Zavarzin. 1987. Methanohalobium evestigatus, n. gen., n. sp. The extremely halophylic methanogenic Archaebacterium. Dokl. Akad. Nauk SSSR 293:464-468. 